\title{
Hypobaric hypoxia causes deleterious effects on spermatogenesis in rats
}

\author{
Weigong Liao, Mingchun Cai, Jian Chen, Jian Huang, Fuyu Liu, Chunhua Jiang and Yuqi Gao \\ Key Laboratory of High Altitude Medicine, Ministry of Education, Department of Pathophysiology and High Altitude \\ Physiology, College of High Altitude Military Medicine, Third Military Medical University, Chongqing 400038, \\ People's Republic of China
}

Correspondence should be addressed to Y Gao; Email: gaoy66@yahoo.com

\begin{abstract}
The study was conducted to explore the effects of hypobaric hypoxia on spermatogenesis in rats. Adult male Wistar rats were randomly divided into four groups: three hypoxia-exposed groups and one normoxic control group. Rats in the normoxic control group were raised at an altitude of $300 \mathrm{~m}$, while rats in the 5-, 15-, and 30-day hypoxic groups were raised in a hypobaric chamber simulating a high altitude of $5000 \mathrm{~m}$ for 5, 15, and 30 days respectively. Flow cytometry was used to detect the DNA content of testicular spermatogenic cells in rats. The apoptosis of germ cells in testis was analyzed by using TUNEL assay. Spermatogenesis was also evaluated by morphology. Flow cytometry analysis revealed that 5-30 days of hypobaric hypoxia exposure significantly reduced the percentage of tetraploid cell population in rat testis. After rats were exposed to hypobaric hypoxia for 30 days, the ratio of haploid and diploid cell populations in testis reduced significantly. Seminiferous tubules with apoptotic germ cell increased after exposure to hypoxia. Most apoptotic germ cells were spermatogonia and spermatocytes. Hypoxia also caused decrease of cellularity of seminiferous epithelium, degeneration and sloughing of seminiferous epithelial cells occasionally. The data suggest that hypobaric hypoxia inhibits the spermatogenesis in rats. Decrease of tetraploid spermatogenic cells (primary spermatocytes) induced by hypoxia is an important approach to suppress spermatogenesis. The apoptosis of primary spermatocytes and spermatogonia may contribute to the loss of tetraploid cell populations.

Reproduction (2010) 139 1031-1038
\end{abstract}

\section{Introduction}

More than 20 million people worldwide live at altitudes above $3000 \mathrm{~m}$ today. Furthermore, every year several hundreds of thousands of people from lowland areas move to higher altitudes for work and travel. But high altitude hypoxia is a challenge for people residing in or visiting high altitudes. Among those physiological effects of hypoxia, it has been suggested that newcomers from low-lying areas have difficulties in fertility at high altitude, though the fertility rate in native residents at high altitudes is not lower than in populations at sea level (Gonzales 2007). Previous studies indicated that hypoxia reduced the fertility of male rats (Gosney 1984), rhesus monkeys (Saxena 1995), and men (Okumura et al. 2003, Verratti et al. 2008) from lowland by decreasing sperm count and sperm motility in semen. Morphological studies in animals revealed that hypoxia caused degeneration of germinal epithelium (Gosney 1984, Saxena 1995). These studies suggested that spermatogenesis was interfered with by hypoxia.

But little is known about which stages of spermatogenesis are mainly affected by hypoxia and how hypoxia affects them. These questions should be answered. Furthermore, in the previous studies, spermatogenesis was evaluated only by employing histological analyses of testes. In contrast, the use of flow cytometry facilitates rapid, sensitive, objective measurements of reproductive effects due to environmental, occupational, and therapeutical exposure to toxicants, by quantitation of large numbers of testicular germ cells. As a consequence, it is widely accepted as an effective method of assessing spermatogenesis in a variety of species, including the rat (Spano \& Evenson 1993).

Apoptosis, also referred to as programmed cell death, is a well-defined physiological process that eliminates individual cells from mammalian tissues. In adult animals, germ cell death is important for spermatogenesis and helps to regulate sperm output (Print \& Loveland 2000, Kierszenbaum 2001). Elimination of germ cells via apoptosis occurs spontaneously under normal physiological conditions and is often heightened after chemical-induced testicular injury (Richburg 2000, Park et al. 2002, Assinder et al. 2007). Thus, it is likely that hypoxia reduces sperm production by promoting apoptosis of germ cells in testis. But it was not 
investigated in previous studies. TUNEL staining of DNA fragments is routinely used for the detection of apoptotic cells in various tissues, and it is also a sensitive and valid method for identification of apoptotic cells within the seminiferous epithelium (Yu et al. 2001).

Therefore, the present investigation was undertaken to evaluate the effects of hypoxia on spermatogenesis in rat testis by flow cytometry, histological examination, and TUNEL assay.

\section{Results}

\section{Histopathological examination}

\section{Light microscopy}

The space between seminiferous tubules was enlarged in rats from the three hypoxic groups. In hypoxic testes, the basal lamina and subepithelial myoid layer appear more undulate. In most sections of hypoxic testes, spermatogonia appear to be losing their attachment to the basal lamina, and other seminiferous cells beyond the maturation step of spermatogonia appear to be losing their cell-to-cell attachments. Examination of testis in hypoxic rats also revealed that the luminal boundary is degraded and lacks the organized clusters of maturing germ cells, which normally characterize the luminal border of the seminiferous epithelium. The percentages of seminiferous tubules with sloughed seminiferous cells in 5-, 15-, and 30-day hypoxic rats were higher than that in control rats $(7.2 \pm 0.9,7.2 \pm 0.8,4.6 \pm 0.5$ vs $0.8 \pm 0.4 \%$ respectively; $P<0.01)$. In some sections, reduced cellularity and degeneration of germ cell were observed in seminiferous epithelium in rats from three hypoxic groups. Sertoli cell vacuolization was also observed in hypoxic rats. However, testes taken from the normobaric control rats did not show these morphological changes. The seminiferous epithelium was well organized, with normal germ cells and Sertoli cells at various stages in control rats (Fig. 1).

\section{Electron microscopy}

Control rat testis did not show any obvious ultrastructural change. In hypoxic rat testes, vacuolation and more lipid droplets were observed in the Sertoli cells. Many myelinlike structures were formed in the cytoplasm of Sertoli cells. Mitochondria distended with loss of cristae. Degenerated spermatogonia with condensated and marginated chromatin were observed in rats exposed to hypoxia for 15 and 30 days. In testes from the 15-day hypoxic exposure rats, some degenerated spermatogonia lost attachment to the surrounding Sertoli cells and basal membrane. Empty spaces left by degenerated germ cells were also observed in rats exposed to hypoxia for 15 and 30 days. Nuclear envelope invaginations were found occasionally in primary spermatocytes in 30-day hypoxic exposure rats (Fig. 2).

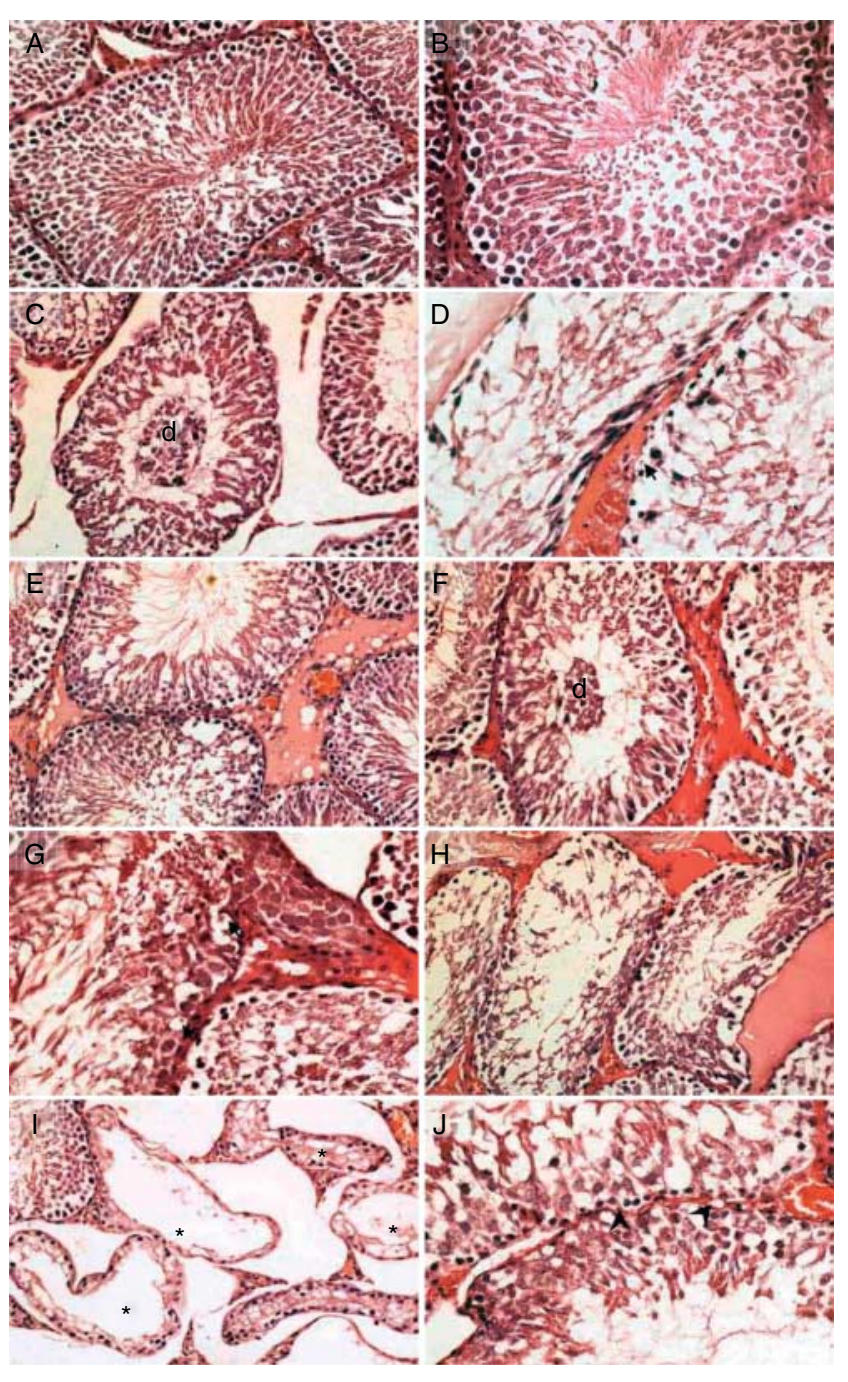

Figure 1 Light microscopy of $\mathrm{H} \& \mathrm{E}-$ stained rat testicular sections. (A and B) Testicular sections from control rats: A, $\times 400 ; B, \times 640$. ( $C$ and $D)$ Testicular sections from rats exposed to hypobaric hypoxia for 5 days: $C$, degenerated germ cells sloughed out into the lumen were visible (d), $\times 400$; D, germ cell degeneration (arrow) and seminiferous epithelial vacuolation were found, $\times 640$. (E-G) Testicular sections from rats exposed to hypobaric hypoxia for 15 days: $\mathrm{E}$, vacuolation was observed, $\times 400$; F, degenerated germ cells (d) and disorganized seminiferous epithelium were found, $\times 400$; G, degenerating germ cells (arrow) were found, $\times 640$. ( $\mathrm{H}-\mathrm{J})$ Testicular sections from rats exposed to hypobaric hypoxia for 30 days: $\mathrm{H}$, disorganized seminiferous epithelium and low levels of cellularity within seminiferous tubules were observed, $\times 400$; I, some degenerating tubules (asterisk) are shown. Spermatogenesis is absent, $\times 400$; J, folding of the basal membrane (tip of the arrows) and seminiferous epithelial vacuolation were observed, $\times 640$.

\section{Flow cytometry analysis}

The flow cytometric DNA content distribution of various germ cells in the control rats is well characterized by the presence of three main distinct peaks, representing spermatid (1C, including elongated spermatid and round spermatid), diploid spermatogonia (2C), and tetraploid primary spermatocyte (4C) populations. 

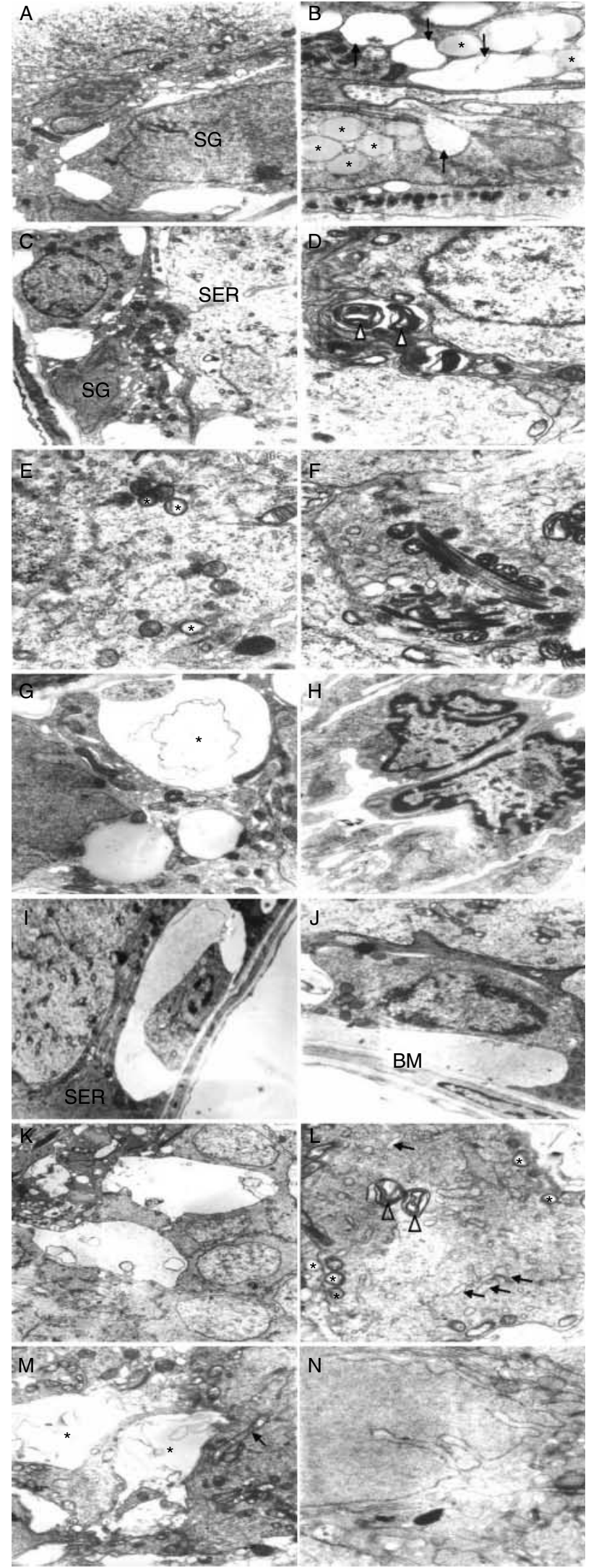

Diploid population includes nongerm cell types like Sertoli cells, Leydig cells, etc. $(<3 \%$ of the total germ cell population), and also includes secondary spermatocytes, whose life time is very short. The region before the haploid peak represents cells with subhaploid DNA content (debris that may be of apoptotic origin; Hacker-Klom et al. 1999).

\section{Alteration in the relative germ cell percentages by hypoxia}

The relative percentages of different testicular germ cell populations in control rats, 5-day hypoxic rats, 15-day hypoxic rats, and 30-day hypoxic rats are shown in Table 1.

\section{Spermatogonia (2C)}

The relative percentage of spermatogonia (2C) in 30-day hypoxic rats was significantly greater than that in control rats $(P<0.01)$. No significant change was observed in 5- and 15-day hypoxic rats as compared with that in control rats $(P>0.05)$.

\footnotetext{
Figure 2 Electron micrographs of seminiferous epithelium. (A) Seminiferous epithelium from control rats showing normal spermatogonia (SG) with homogeneous chromatin, $\times 7000$. (B) Seminiferous epithelium from rats exposed to hypoxia for 5 days, showing Sertoli cells with vacuoles (arrows) and lipid droplets (asterisks) within the cytoplasm, $\times 10$ 000. (C) Seminiferous epithelium from rats exposed to hypoxia for 5 days, showing degenerated spermatogonia (SG) about to be phagocytosed by a Sertoli cell (SER), $\times 4200$. (D) Seminiferous epithelium from rats exposed to hypoxia for 5 days, showing multilayered myelin-like figures in cytoplasm (arrowhead), $\times 10$ 000. (E) Seminiferous epithelium from rats exposed to hypoxia for 5 days, showing swollen mitochondria with reduced cristae (asterisks), $\times 14$ 000. (F) Seminiferous epithelium from rats exposed to hypoxia for 5 days, showing incomplete mitochondrial sheath surrounding sperm tail, $\times 14$ 000. (G) Seminiferous epithelium from rats exposed to hypoxia for 15 days, showing late apoptotic spermatogonia (asterisk), $\times 7000$. (H) Seminiferous epithelium from rats exposed to hypoxia for 15 days, showing degenerated germ cells with abnormal shape of nuclei and marginated chromatin, $\times 10000$. (I) Seminiferous epithelium from rats exposed to hypoxia for 15 days, showing spermatogonia with marginated and condensated chromatin detached from the surrounding Sertoli cells (SER). Shrinkage of cytoplasm and nucleus was observed, $\times 4200$. (J) Seminiferous epithelium from rats exposed to hypoxia for 15 days, showing spermatogonia with marginated and condensated chromatin detached from basal membrane (BM), $\times 7000$. (K) Seminiferous epithelium from rats exposed to hypoxia for 15 days, showing a cluster of empty spaces left by degenerated germ cells, $\times 2100$. (L) Seminiferous epithelium from rats exposed to hypoxia for 30 days, showing multilayered myelinlike figures (arrowhead), degenerative mitochondria (asterisks), and enlarged endoplasmic reticulum (arrow), $\times 10$ 000. (M) Seminiferous epithelium from rats exposed to hypoxia for 30 days, showing empty spaces (asterisk) left by degenerated germ cell and abnormal giant mitochondria (arrow) in cytoplasm of surrounding Sertoli cell, $\times 7000$. (N) Seminiferous epithelium from rats exposed to hypoxia for 30 days, showing invaginations of nuclear envelope in primary spermatocyte, $\times 10000$.
} 
Table 1 Alteration in the relative germ cell percentages by hypoxia (\%, $n=6)$.

\begin{tabular}{llrr}
\hline & Sub-1C cells & 1C cells & 4C cells \\
\hline Control group & $1.30 \pm 0.13$ & $73.04 \pm 1.03$ & $9.45 \pm 0.51$ \\
5-day hypoxic group & $1.98 \pm 0.17$ & $75.70 \pm 0.76^{*}$ & $9.12 \pm 0.59$ \\
15-day hypoxic group & $2.18 \pm 0.33^{*}$ & $75.26 \pm 0.78$ & $11.67 \pm 0.28^{\dagger}$ \\
30-day hypoxic group & $3.08 \pm 0.38^{+}$ & $71.20 \pm 0.76^{*}$ & $10.47 \pm 0.50$ \\
\hline
\end{tabular}

${ }^{*} P<0.05 ;{ }^{\dagger} P<0.01$ compared with control group.

\section{Primary spermatocytes (4C)}

The relative percentage of primary spermatocytes $(4 \mathrm{C})$ in $5-, 15-$, and 30-day hypoxic rats showed significant decline as compared with that in control rats $(P<0.01)$.

\section{Spermatids (1C)}

Exposure of rats to hypoxia for 5 and 15 days resulted in a significant increase of relative percentages of spermatids compared with normoxic exposure $(P<0.05)$. However, the relative percentage of spermatids in 30-day hypoxic rats did not change significantly $(P>0.05$, compared with control rats).

\section{Sub-haploid cells}

The relative percentage of sub-haploid cells was significantly more in rats from 15- to 30-day hypoxic groups than that in rats from control group $(P<0.05$ and $P<0.01$ respectively). No significant difference in relative percentage of sub-haploid cells was observed between 5 -day hypoxic group and control group $(P>0.05)$.

\section{Alteration in the relative germ cell ratios by hypoxia}

The ratios of different germ cell in 5-, 15-, 30-day hypoxic rats and control rats are presented in Table 2.

\section{C:2C ratio}

A significant decline of $4 \mathrm{C}: 2 \mathrm{C}$ ratio in 15- and 30-day hypoxic rats was observed as compared with that in control rats $(P<0.01)$. There was no significant difference in the $4 \mathrm{C}: 2 \mathrm{C}$ ratio between 5 -day hypoxic rats and control rats $(P>0.05)$.

\section{C:2C ratio}

Exposure of rats to hypoxia for 30 days resulted in a significant decline in $1 \mathrm{C}: 2 \mathrm{C}$ ratio compared with normoxic exposure $(P<0.01)$. No obvious change of

Table 2 Alteration in the relative germ cell ratios by hypoxia $(n=6)$.

\begin{tabular}{llll}
\hline & 1C:2C & 1C:4C & 4C:2C \\
\hline Control group & $7.84 \pm 0.45$ & $5.21 \pm 0.33$ & $1.53 \pm 0.10$ \\
5-day hypoxic group & $8.48 \pm 0.57$ & $6.51 \pm 0.20^{*}$ & $1.30 \pm 0.08$ \\
15-day hypoxic group & $7.28 \pm 0.36$ & $7.24 \pm 0.40^{\dagger}$ & $1.03 \pm 0.09^{+}$ \\
30-day hypoxic group & $5.86 \pm 0.15^{+}$ & $6.93 \pm 0.34^{+}$ & $0.86 \pm 0.05^{+}$ \\
\hline
\end{tabular}

${ }^{*} P<0.05 ;{ }^{\dagger} P<0.01$ compared with control group.
1C:2C ratio was found between control rats and either of 5 - and 15-day hypoxic rats $(P>0.05$, compared with control rats).

\section{C:4C ratio}

The $1 \mathrm{C}: 4 \mathrm{C}$ ratio exhibited a significant increase in 5-day hypoxic rats $(P<0.05), 15$-day hypoxic rats, and 30-day hypoxic rats $(P<0.01)$ as compared with that in control rats.

\section{TUNEL}

Most of the TUNEL-positive germ cells were detected to be primary spermatocytes and spermatogonia, while few apoptotic spermatids and nongerm cells were observed. Apoptosis in testis was quantitated using a scoring system based on the percentage of the seminiferous tubules with TUNEL-positive cells (Blanchard et al. 1996, Richburg 2000, Yamamoto et al. 2002). The percentages of seminiferous tubules with TUNEL-positive cells in 5 -day hypoxic rats $(P<0.01), 15$-day hypoxic rats $(P<0.01)$, and 30 -day hypoxic rats $(P<0.05)$ were more than that in control rats (Figs 3 and 4).

\section{Discussion}

This hypoxic rat model has been widely used by our lab and other labs to research the effects of high-altitude hypoxia on the body. The decompressing treatment did not obviously exacerbate the severity of the high-altitude effects on rats. No signs of high-altitude sicknesses such as cerebral or pulmonary edema were observed in these rats.

In this study, we found hypoxia caused damage to the germinal epithelium, folding of the basal membrane, degeneration and sloughing of spermatogenic cells in lumen of seminiferous tubule. We also observed that hypoxia caused lipid droplet deposition in Sertoli cells and spermatogonia degeneration with chromatin margination under electron microscopy. These changes of morphology in testes indicate that hypoxia impairs spermatogenesis in rats. Previous studies also revealed that hypoxia impaired spermatogenesis in testis by light microscopic analyses. The morphological changes in testis are attributed to the vulnerability of spermatogenesis to hypoxia. Men and male animals produce a great amount of sperm every day, indicating that 


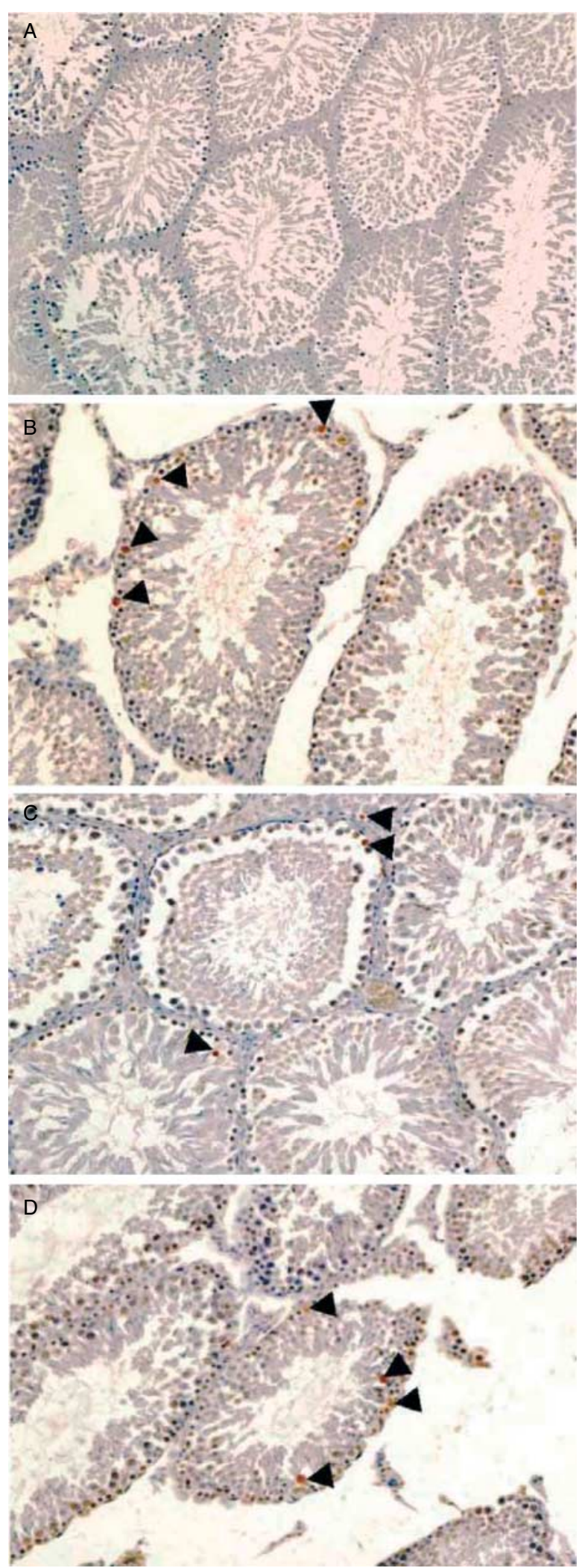

Figure 3 Immunohistochemical demonstration of apoptotic cells by the TUNEL method. (A) Control rats, magnification: $\times 200$; (B) 5-day hypoxic rats, magnification: $\times 320$; (C) 15 -day hypoxic rats, magnification: $\times 320$; (D) 30-day hypoxic rats, magnification: $\times 320$. spermatogenesis in the seminiferous tubules of the testis occurs under a high proliferation rate, which demands considerable oxygen consumption. However, blood vessels are located exclusively between the tubules, and oxygen reaches the lumen of the seminiferous tubules only by diffusion. The seminiferous epithelium was speculated to operate on the verge of hypoxia because the testicular $\mathrm{PO}_{2}$ is relatively low, oxygen extraction is highly related to the metabolic demands of spermatogenesis, oxygen diffusion distance is comparatively long, and the testis has little capacity to increase total blood flow (Lysiak et al. 2000). Furthermore, exposure to hypoxia results in distribution of blood flow to the vital organs including brain and heart, and decrease in testicular blood flow. Koskinen et al. (2000) reported that breathing $10 \% \mathrm{O}_{2} / 90 \% \mathrm{~N}_{2}$ resulted in a $24 \%$ decrease in testicular blood flow, but a $23 \%$ increase in cerebral blood flow. These characteristics may attribute to the morphological changes of spermatogenesis caused by hypoxia.

In this study, we also observed that hypoxia increases interstitial space of testis, which extends the oxygen diffusion distance and would impair oxygen delivery to germ cells. It makes germ cells more susceptible to damage, which was confirmed by our observation of degenerative germ cells in hypoxic rats under light and EM. A similar change was reported by Farias et al. (2005a).

Besides these, an increase in testicular temperature may be another factor involved in impairing spermatogenesis under hypobaric hypoxia (Farias et al. 2005b).

To explore which stages of spermatogenesis are mainly affected by hypoxia, flow cytometry was employed in this study. Flow cytometry can provide a rapid way to investigate germinal epithelium integrity and to perform a quantitative analysis of spermatogenesis, and it has been used in many laboratories to examine spermatogenesis in men and animals. In the present study, the relative percentage of $1 \mathrm{C}$ cells increased in 5- and 15-day hypoxic rats, which may be caused by inhibition of mature sperm release from spermatogenic epithelium. As a result, less sperm would enter the epididymal initial segment, and less sperm would reach the epididymal cauda 8 days later ( 8 days for the transit of spermatozoa from the epididymal initial segment to the proximal cauda in the rat). This was confirmed in our laboratory. We observed that epididymal caudal sperm reduced significantly after rats were exposed to hypobaric hypoxia for 15 and 30 days, while it did not significantly change after a 5-day exposure to hypobaric hypoxia. Gasco et al. (2003) also observed that the epididymal sperm count was significantly reduced at days 14,28 , and 35 , but not reduced at days 3 . These results suggest that hypoxia inhibits the release of sperm from the spermatogenic epithelium. However, the relative percentage of $1 \mathrm{C}$ cells in 30-day hypoxic rats did not significantly differ from the control. It was because hypoxia on the one hand decreased 


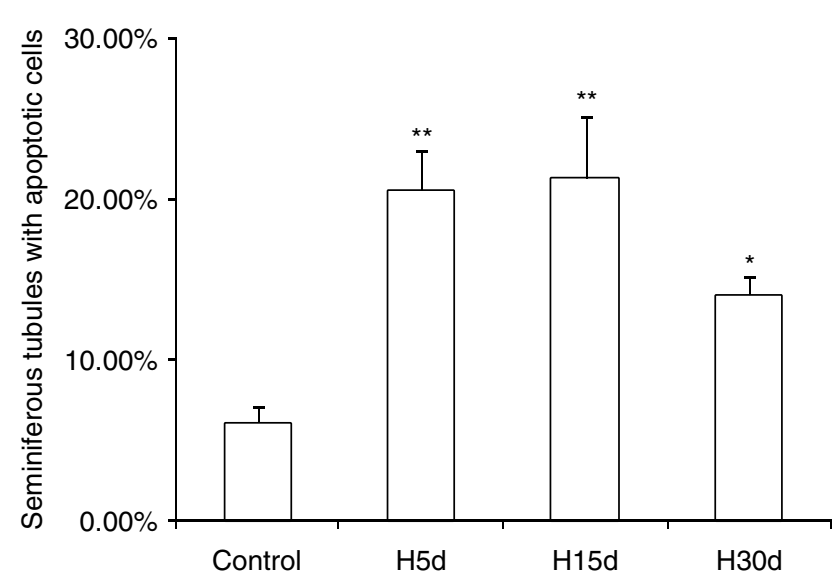

Figure 4 Effect of hypoxia on germ cell apoptosis in testis $(n=4$; ${ }^{*} P<0.05 ;{ }^{* *} P<0.01$ compared with control group).

spermatid number by restraining the spermatogenesis; on the other hand, it increased the amount of sperm in the testis by inhibition of sperm release from spermatogenic epithelium. The duration of spermatogenic transformation from spermatogonia to spermatid is 29.5 days in male rats (Adler 1996). Therefore, the inhibition of spermatogenesis is obvious only after a 30-day exposure to hypoxia, which was supported by our result that the total spermatogenic transformation (1C:2C cell ratio) dropped only in 30-day hypoxic rats. The inhibition of spermatogenesis neutralized the increase of the relative percentage of $1 \mathrm{C}$ cells caused by inhibition of sperm release from spermatogenic epithelium in 30-day hypoxic rats. The relative percentage of $2 \mathrm{C}$ cells increased significantly in 30-day hypoxic rats, when compared with that in control rats. Such an increase in relative percentage of $2 \mathrm{C}$ cells is related to the loss of primary spermatocytes and decrease of spermatid. The flow cytometry also provided convincing evidence that the suppressive effects of hypoxia on spermatogenesis were mainly caused by decreasing tetraploid spermatogenic cells. This was supported by the observations that the ratios of tetraploid to diploid cells were low and proportions of tetraploid cells were significantly decreased in rats exposed to hypoxia for 5 , 15 , and 30 days.

Increase of apoptosis in germ cells is an important mechanism, through which many reported that toxic substances inhibit spermatogenesis and decrease the production of mature sperm. Germ cell apoptosis induced by hypobaric hypoxia was not evaluated in previous studies. TUNEL assay is routinely used for the accurate detection of apoptotic cells in various tissues, which relies on abundance of $3^{\prime}$ DNA ends generated by DNA fragmentation in apoptotic cells. In the present study, we evaluated germ cell apoptosis induced by hypoxia simulated to a high altitude of $5000 \mathrm{~m}$ by TUNEL assay. In the present study, several sporadically distributed apoptotic cells were observed in control rats. This is in agreements with previous studies (Blanco-Rodriguez \& Martinez-Garcia 1996, Zhang et al. 2001, Xiong et al. 2009), suggesting that apoptosis is an important mechanism in controlling numbers of germ cells. The percentage of seminiferous tubules containing apoptotic germ cells increased in hypoxic rats at 5, 15, and 30 days. Most apoptotic germ cells were spermatogonia and primary spermatocytes. As a result of the apoptosis of spermatogonia and primary spermatocytes, a decline in the tetraploid cell population was detected in hypoxic rats by flow cytometry.

\section{Conclusions}

Hypobaric hypoxia inhibits spermatogenesis in rats by decreasing the tetraploid spermatogenic cells (primary spermatocytes). The apoptosis of primary spermatocytes and spermatogonia, induced by hypoxia, may contribute to the loss of the tetraploid cell population.

\section{Materials and Methods}

\section{Animals}

Adult male Wistar rats were randomly divided into four groups: control group, 5-, 15-, and 30-day hypoxic groups. Hypoxic rats were raised in a hypobaric chamber, where atmospheric pressure was reduced to simulate high altitude of $5000 \mathrm{~m}$. The partial pressure of nitrogen fell as total pressure declines on ascent, but nitrogen percentage did not change in atmosphere. Hypoxic rats were returned to normobaric condition for $40 \mathrm{~min}$ every day when food and water were provided, and cages were cleaned. The ascending speed and descending speed for the hypobaric chamber were limited to $4-5 \mathrm{~m} / \mathrm{s}$. Control rats were raised at an altitude of $300 \mathrm{~m}$ out of the hypobaric chamber. All the animals had free access to standard pellet food and water, and they were maintained under controlled light conditions (12 h light:12 $\mathrm{h}$ darkness). The experiments were approved by the Animal Care Committee of the Third Military Medical University. All efforts were made to minimize animal suffering and the number of animals used.

\section{Histopathological examination}

\section{Light microscopy}

Animals were killed by decapitation. Left testes were excised, fixed in $10 \%$ formalin, dehydrated, and embedded in paraffin. Sections were cut at $5 \mu \mathrm{m}$ thickness and were stained with hematoxylin and eosin for light microscopic observations.

\section{Electron microscopy}

Testes were sliced and fixed in 3\% glutaraldehyde. Ultrathin sections were stained in uranyl acetate and lead citrate, and they were observed in a Phillips TECNAI 10 transmission electron microscope. 


\section{Flow cytometry}

The germ cells were released from seminiferous tubules in PBS, by mincing $200 \mathrm{mg}$ right testicular tissue finely with scissors, and then digesting the tissue with $200 \mathrm{mg} / \mathrm{l}$ collagenase (Sigma) at $37^{\circ} \mathrm{C}$ for $30 \mathrm{~min}$. Sertoli cell aggregates and clumped debris were removed by filtering through a nylon mesh twice and were centrifuged for $10 \mathrm{~min}$ at $500 \mathrm{~g}$. Pellet was washed twice and fixed in $70 \%$ chilled ethanol. The samples were stored at $4{ }^{\circ} \mathrm{C}$. After germ cells were stained with $25 \mathrm{mg} / \mathrm{l}$ ethidium bromide (Sigma), the tubes were kept in dark at room temperature for $30 \mathrm{~min}$ before flow cytometry analysis. The samples were analyzed by a FACScan flow cytometer (BD Biosciences, San Jose, CA, USA) using an excitation wavelength of $488 \mathrm{~nm}$.

\section{TUNEL immunohistochemistry}

Immunohistochemical apoptotic detection (TUNEL assay) was performed on $10 \%$ formalin-fixed $5 \mu \mathrm{m}$ paraffin sections using In Situ Cell Death Detection Kit (POD, Roche). Briefly, after dewaxing and rehydrating, the tissue sections were incubated with $25 \mathrm{mg} / \mathrm{l}$ proteinase $\mathrm{K}$ for $20 \mathrm{~min}$ at $37^{\circ} \mathrm{C}$. Nonspecific labeling was blocked by pre-incubating the sections with $3 \%$ $\mathrm{H}_{2} \mathrm{O}_{2}$ in methanol for $10 \mathrm{~min}$ at room temperature. To each section, $50 \mu \mathrm{l}$ of TUNEL reaction mixture were added and incubated for $60 \mathrm{~min}$ at $37^{\circ} \mathrm{C}$ in a humidified atmosphere. After sections were rinsed, $50 \mu \mathrm{l}$ of converter-POD were added on each section and incubated for $30 \mathrm{~min}$ in a humidified chamber at $37^{\circ} \mathrm{C}$. Sections were rinsed again and incubated with $100 \mu \mathrm{l}$ DAB substrate for $10 \mathrm{~min}$ at room temperature. Color developing was stopped by washing the sections with PBS. Sections were counterstained with hematoxylin. For the negative control, TUNEL reaction mixture was replaced by the same volume of reaction buffer. The percentage of seminiferous tubules containing brown staining cell was analyzed.

\section{Statistical analysis}

Data were expressed as mean \pm S.E.M. SPSS 10.0 software (SPSS Inc., Chicago, IL, USA) was used for statistical analyses. Differences in the mean values between the control group and each of three other groups were examined by one way ANOVA, followed by least significant difference multiple comparison test. Differences were considered significant when the $P$ value was $<0.05$.

\section{Declaration of interest}

The authors declare that there is no conflict of interest that could be perceived as prejudicing the impartiality of the research reported.

\section{Funding}

This work was supported by grants from the National Natural Science Foundation of China (grant number 30872764) and the Major State Basic Research Development Program of China (grant number 2006CB406100).

\section{Acknowledgements}

The authors would like to thank Xiaolan Fu for her help in acquiring data on the flow cytometer. The authors would also like to thank Jinxing Ke for his technical assistance in electron microscopy.

\section{References}

Adler ID 1996 Comparison of the duration of spermatogenesis between male rodents and humans. Mutation Research 352 169-172.

Assinder S, Davis R, Fenwick M \& Glover A 2007 Adult-only exposure of male rats to a diet of high phytoestrogen content increases apoptosis of meiotic and post-meiotic germ cells. Reproduction 133 11-19.

Blanchard KT, Allard EK \& Boekelheide K 1996 Fate of germ cells in 2,5-hexanedione-induced testicular injury. I. Apoptosis is the mechanism of germ cell death. Toxicology and Applied Pharmacology 137 141-148.

Blanco-Rodriguez J \& Martinez-Garcia C 1996 Spontaneous germ cell death in the testis of the adult rat takes the form of apoptosis: re-evaluation of cell types that exhibit the ability to die during spermatogenesis. Cell Proliferation 29 13-31.

Farias J, Bustos Obregón E, Orellana R, Bucarey J, Quiroz E \& Reyes J 2005 a Effects of chronic hypobaric hypoxia on testis histology and round spermatid oxidative metabolism. Andrologia 37 47-52.

Farias JG, Bustos-Obregon E \& Reyes JG 2005b Increase in testicular temperature and vascularization induced by hypobaric hypoxia in rats. Journal of Andrology 26 693-697.

Gasco M, Rubio J, Chung A, Villegas L \& Gonzales GF 2003 Effect of high altitude exposure on spermatogenesis and epididymal sperm count in male rats. Andrologia 35 368-374.

Gonzales GF 2007 Peruvian contributions to the study on human reproduction at high altitude: from the chronicles of the Spanish conquest to the present. Respiratory Physiology \& Neurobiology 158 172-179.

Gosney JR 1984 Effects of hypobaric hypoxia on the Leydig cell population of the testis of the rat. Journal of Endocrinology 103 59-62.

Hacker-Klom UB, Gohde W, Nieschlag E \& Behre HM 1999 DNA flow cytometry of human semen. Human Reproduction 14 2506-2512.

Kierszenbaum AL 2001 Apoptosis during spermatogenesis: the thrill of being alive. Molecular Reproduction and Development 58 1-3.

Koskinen LO, Collin O \& Bergh A 2000 Cigarette smoke and hypoxia induce acute changes in the testicular and cerebral microcirculation. Upsala Journal of Medical Sciences 105 215-226.

Lysiak JJ, Nguyen QA \& Turner TT 2000 Fluctuations in rat testicular interstitial oxygen tensions are linked to testicular vasomotion: persistence after repair of torsion. Biology of Reproduction 63 1383-1389.

Okumura AFH, Kawauchi Y, Mizuno I \& Akashi T 2003 Changes in male reproductive function after high altitude mountaineering. High Altitude Medicine \& Biology 4 349-353.

Park JD, Habeebu SS \& Klaassen CD 2002 Testicular toxicity of di(2-ethylhexyl)phthalate in young Sprague-Dawley rats. Toxicology $\mathbf{1 7 1}$ 105-115.

Print CG \& Loveland KL 2000 Germ cell suicide: new insights into apoptosis during spermatogenesis. BioEssays 22 423-430.

Richburg JH 2000 The relevance of spontaneous- and chemically-induced alterations in testicular germ cell apoptosis to toxicology. Toxicology Letters 112-113 79-86.

Saxena DK 1995 Effect of hypoxia by intermittent altitude exposure on semen characteristics and testicular morphology of male rhesus monkeys. International Journal of Biometeorology 38 137-140.

Spano M \& Evenson DP 1993 Flow cytometric analysis for reproductive biology. Biology of the Cell 78 53-62.

Verratti VBF, Di Giulio C, Bosco G, Cacchio M, Pellicciotta M, Nicolai M, Martinotti S \& Tenaglia R 2008 Evidence that chronic hypoxia causes reversible impairment on male fertility. Asian Journal of Andrology $\mathbf{1 0}$ 602-606.

Xiong W, Wang H, Wu H, Chen Y \& Han D 2009 Apoptotic spermatogenic cells can be energy sources for Sertoli cells. Reproduction 137 469-479. 
Yamamoto Y, Yamamoto K, Hayase T, Abiru H, Shiota K \& Mori C 2002 Methamphetamine induces apoptosis in seminiferous tubules in male mice testis. Toxicology and Applied Pharmacology $\mathbf{1 7 8}$ 155-160.

Yu X, Kubota H, Wang R, Saegusa J, Ogawa Y, Ichihara G, Takeuchi Y \& Hisanaga $\mathbf{N} 2001$ Involvement of Bcl-2 family genes and Fas signaling system in primary and secondary male germ cell apoptosis induced by 2-bromopropane in rat. Toxicology and Applied Pharmacology 174 35-48.
Zhang X, Yamamoto N, Soramoto S \& Takenaka I 2001 Cisplatin-induced germ cell apoptosis in mouse testes. Archives of Andrology 46 43-49.

Received 15 December 2009

First decision 5 February 2010

Revised manuscript received 9 March 2010

Accepted 16 March 2010 